\title{
BMJ Open Photobiomodulation therapy associated with supervised therapeutic exercises for people with knee osteoarthritis: a randomised controlled trial protocol
}

\author{
Ana E S Jorge (D) , ${ }^{1}$ Lucas O Dantas (D) , ${ }^{1}$ Paula R M S Serrão (D) , \\ Francisco Alburquerque-Sendín (D) ,2 Tania F Salvini (D) ${ }^{1}$
}

To cite: $S$ Jorge $A E, 0$ Dantas L, M S Serrão PR, et al. Photobiomodulation therapy associated with supervised therapeutic exercises for people with knee osteoarthritis: a randomised controlled trial protocol. BMJ Open 2020;0:e035711. doi:10.1136/ bmjopen-2019-035711

- Prepublication history and additional material for this paper are available online. To view these files, please visit the journal online (http://dx.doi. org/10.1136/bmjopen-2019035711).

Received 13 November 2019 Revised 11 March 2020 Accepted 13 March 2020

Check for updates

(c) Author(s) (or their employer(s)) 2020. Re-use permitted under CC BY-NC. No commercial re-use. See rights and permissions. Published by BMJ.

${ }^{1}$ Department of Physiotherapy, Federal University of Sao Carlos, São Carlos, São Paulo, Brazil

${ }^{2}$ Department of Sociosanitary Sciences, Radiology and Physical Medicine, Universidad de Córdoba, Instituto

Maiomónides de Investigación Biomédica de Córdoba (IMIBIC), Córdoba, Andalucía, Spain

Correspondence to

Dr Tania F Salvini;

tania@ufscar.br

\section{ABSTRACT}

Background Physical exercise, a cornerstone of the conservative management of knee osteoarthritis (KOA), is exhaustively recommended by important clinical guidelines. A strength therapeutic exercise program (STEP) relieves pain, improves physical function and ultimately ameliorates quality of life (QoL). Furthermore, photobiomodulation (PBM) has been used as an adjunct treatment for people with $\mathrm{KOA}$; however, there are still controversial recommendations regarding its use on this population. Thus, we hypothesised that PBM, when associated with a STEP protocol on patients with KOA, could induce better clinical outcomes than a STEP protocol alone.

Methods and analysis The study is a 6-month tripleblind placebo-controlled randomised clinical trial with intention-to-treat analysis. The trial will include 120 people with clinic and radiographic signs of KOA. The intervention consists of a supervised STEP and PBM protocols conducted over an 8-week intervention period. Assessments are performed at baseline, right after treatment, and 3-month and 6-month follow-up periods. The primary clinical outcome is pain intensity according to a $10 \mathrm{~cm}$ Visual Analogue Scale. Secondary outcomes are the global Western Ontario \& McMaster Universities Osteoarthritis Index; QoL assessed by the 36-item ShortForm health survey questionnaire; and performance-based physical parameters assessed by the $30 \mathrm{~s}$ chair stand test; the stair climb test; and the $40 \mathrm{~m}$ fast-paced walk test. Ethics and dissemination The trial was approved by the Human Research Ethics Committee of the Federal University of São Carlos, São Paulo, Brazil (REC no 2.016.122). Results will be published in peer-reviewed journals.

Trial registration number Brazilian Clinical Trials Registry (U1111-1215-6510).

\section{BACKGROUND}

Knee osteoarthritis (KOA) causes chronic pain and physical function impairments and ultimately reduces patients' quality of life (QoL). ${ }^{1}$ This disease affects almost $25 \%$ of adults $^{23}$ and is ranked as the 13th leading cause to global disability according to the Global Burden of Disease Study 2013. ${ }^{4}$ Thus,
Strengths and limitations of this study

- The trial followed well-established reporting guidelines to improve the scientific evidence regarding this topic. The methodology was designed to minimise the potential for bias by including concealed treatment allocation and blinding of the outcome assessor and biostatistician.

- Participants presented radiographically confirmed knee osteoarthritis and a sufficient level of pain to ensure ample scope for improvement.

- Photobiomodulation parameters are not tailored according to the skin colour of the participants, which could attenuate the total light energy delivered depending on the melanin content.

it imposes an enormous impact on the patient as well as a huge socioeconomic cost. ${ }^{5}$

Physical exercise, alongside with patient education and weight loss, is undoubtedly the cornerstone of conservative nonpharmacological management of KOA and is exhaustively recommended by important clinical guidelines. ${ }^{6-8}$ A strength therapeutic exercise program (STEP) relieves pain, reduces stiffness, improves physical function and ultimately ameliorates QoL and presents the high-quality scientific evidence for KOA. ${ }^{9}{ }^{10}$ In order to obtain better outcomes, prescribed exercise programs should be individualised, based on clinical findings of the patient. Some protocols have low exercise adherence and are underutilised mainly due to the people's beliefs, socioeconomical barriers, fear of movement, among other factors. ${ }^{1112}$ Therefore, there is a need for science-based STEP protocols that are tailored and cost-effective for patients with KOA and that can help researchers and clinicians target rehabilitation.

Adjunct treatments, such as laser therapy, thermal agents, therapeutic ultrasound and 
electrical stimulation, are associated with therapeutic exercises for clinical improvement in patients with KOA. ${ }^{13} 14$ Photobiomodulation (PBM) - the term of choice for low-level laser therapy according to an international consensus ${ }^{15}$-is also used as a non-pharmacological adjunct treatment for osteoarthritis, as it modulates the synovial inflammatory process and may reduce pain. ${ }^{16-18}$ The therapy is applied locally, which minimises risks, adverse effects, and reduces the indiscriminate use of analgesics and anti-inflammatory drugs by patients. ${ }^{19}$ Although some clinical trials have investigated the isolated short-term effect of $\mathrm{PBM}$ on $\mathrm{KOA}^{20-22}$ there are few reports in the literature regarding the association of PBM with therapeutic exercise programs. ${ }^{23}{ }^{24} \mathrm{~A}$ randomised controlled trial published in 2017 reported an analysis of the residual (long term) effects of a PBM for people with KOA; however, they had performed 3 weeks of PBM therapy protocol alone, before the 8-week exercise protocol..$^{25}$ In addition, the current systematic reviews $^{26-28}$ are still controversial regarding the use of $\mathrm{PBM}$ in patients with KOA. To summarise, two of them ${ }^{26} 28$ report a significant difference between PBM and placebo in terms of pain intensity at rest and on movement and the Western Ontario \& McMaster Universities Osteoarthritis (WOMAC) function; conversely, another systematic review $^{27}$ reports that there was no significant difference in those outcomes (pain and function), stating that the literature does not support PBM therapy for patients with KOA.

This paper presents the design of a STEP+PBM trial. The objective of the randomised trial is to investigate wether the PBM causes any additional benefit to a supervised STEP intervention for pain, physical function and QoL in people with KOA. The STEP protocol described in this study has been developed by our research group and has been also used in another randomised trial testing the complementary effects of cryotherapy in people with KOA (trial registration number: NCT03360500). This manuscript has been submitted simultaneously with the manuscript entitled 'Cryotherapy associated with tailored land-based exercises for individuals with knee osteoarthritis: a protocol for a randomised trial'.

\section{METHODS}

This study protocol was designed and conducted according to the proposed criteria of the 'Standard Protocol Items: Recommendations for Interventional Trials ${ }^{29}$; the 'Osteoarthritis Research Society International (OARSI) clinical trial recommendations: design, conduct and reporting of clinical trials for knee osteoarthritis', $;^{30}$ and the 'Template for Intervention Description and Replication' checklist. ${ }^{31}$ The randomised trial will be reported according to the Consolidated Standards of Reporting Trials statement for randomised trials of nonpharmacological treatments. $^{32}$

\section{Study design}

This study is a single-centre, triple-blind, prospective 6-month parallel design placebo-controlled randomised clinical trial. Participants are randomly allocated into one of the three groups: STEP+active PBM, STEP+inactive PBM (placebo) or STEP +10 min of rest. Verbal and written explanations of the study are provided to all the participants, who sign a written informed consent form approved by the ethics committee. A detailed timeline of the trial is presented in table 1.

\section{Patients and public involvement}

The patients and public were not involved in the planning and design of this study.

\section{Participants}

Participants are recruited through public advertisements on social media, via local news, University community newsletters, and banners and leaflets posted at strategic urban locations. People who are interested undergo a screening process, and radiography examinations of both knees are performed. They are classified with KOA based on the clinical and radiographic criteria of the American College of Rheumatology. ${ }^{33}$ It is mandatory to present symptoms and a radiographic grade of $\geq 2$ (at least mild radiographic OA) based on Kellgren and Lawrence scale in at least one knee compartment. ${ }^{30}$ Participants need to be aged between 40 and 75 years and have pain intensity in the prior week of $\geq 4 \mathrm{~cm}$ on a $10 \mathrm{~cm}$ Visual Analogue Scale. ${ }^{30}$ Exclusion criteria comprise being engaged in a formal strength training program for $>120 \mathrm{~min} /$ week; body mass index $\geq 35 \mathrm{~kg} / \mathrm{m}^{2}$; physical therapy in the prior 3 months; intra-articular knee injections in the prior 6 months; cardiorespiratory, neurological or any other rheumatology conditions that could impose restrictions; previous hip, knee or ankle surgeries; and any other chronic condition that leads to chronic pain or dysfunction. Each participant is required to present a medical clearance to perform physical exercises.

\section{Interventions}

At the beginning of the study, two therapists responsible for applying the intervention participated in a 10-hour class, which consisted of scientific information and clinical training regarding KOA, the STEP protocol and the application of PBM. The $90 \mathrm{~min}$ sessions are conducted three times per week for 8 weeks, totalling 24 sessions, at the physiotherapy clinic of the Federal University of São Carlos, Brazil. All the participants perform the STEP protocol. Afterward, according to the allocation, they receive active or inactive PBM therapy or remain at rest for $10 \mathrm{~min}$.

\section{STEP protocol}

The 8-week land-based supervised exercise protocol was designed according to the recommendations and guidelines of evidence-based practices and specific randomised clinical trials of physical exercise intervention for KOA. ${ }^{3435}$ 
Table 1 Timeline of the study phases

\begin{tabular}{|c|c|c|c|c|c|c|}
\hline & Enrolment & $\begin{array}{l}\text { Baseline } \\
\text { assessment } \\
\text { (A1) }\end{array}$ & Intervention & $\begin{array}{l}\text { Postintervention } \\
\text { assessment } \\
\text { (A2) }\end{array}$ & $\begin{array}{l}\text { Follow-up } \\
\text { assessment } \\
\text { (A3) }\end{array}$ & $\begin{array}{l}\text { Follow-up } \\
\text { assessment } \\
\text { (A4) }\end{array}$ \\
\hline Study phase & Prior 3 weeks & Day 0 & $\begin{array}{l}\text { Week } 1 \text { to } 8 \\
3 \times / \text { week }\end{array}$ & $\begin{array}{l}\text { Week } 9 \\
\text { ( } \pm 3 \text { days) }\end{array}$ & $\begin{array}{l}\text { Week } 21 \\
( \pm 3 \text { days })\end{array}$ & $\begin{array}{l}\text { Week } 33 \\
( \pm 3 \text { days })\end{array}$ \\
\hline \multicolumn{7}{|l|}{ Enrolment } \\
\hline Eligibility screening & $x$ & & & & & \\
\hline Allocation & & & $x$ & & & \\
\hline STEP & & & $x$ & & & \\
\hline STEP+PBM & & & $x$ & & & \\
\hline STEP+sham PBM & & & $x$ & & & \\
\hline WOMAC & & $x$ & & $x$ & $x$ & $x$ \\
\hline SF-36 & & $x$ & & $x$ & $x$ & $x$ \\
\hline 30 s chair stand test & & $x$ & & $x$ & $x$ & $x$ \\
\hline Stair climb test & & $x$ & & $x$ & $x$ & $x$ \\
\hline $\begin{array}{l}40 \mathrm{~m} \text { fast-paced walk } \\
\text { test }\end{array}$ & & $x$ & & $x$ & $x$ & $x$ \\
\hline
\end{tabular}

PBM, photobiomodulation; SF-36, 36-Item Short-Form survey; STEP, strength therapeutic exercise program; VAS, Visual Analogue Scale ; WOMAC, Western Ontario \& McMaster Universities Osteoarthritis Index.

The STEP protocol is detailed in the online supplementary appendix A.

The STEP protocol is divided into two phases. Each phase consists of 4 weeks of progressive exercises, with tailored intensity for each participant, performed three times per week in non-consecutive days. The first session introduces participants to proper techniques of the STEP protocol and allows them to perform an exercise familiarisation. In order to increment the load and achieve the benefits of resistance training, the volitional interruption method is used, providing a low risk of musculoskeletal injuries to the participants. ${ }^{36}$ The participants start using no loads, which are gradually increased (by $1 \mathrm{~kg}$ for free weights or by the elastic band resistance) until they are able to adequately perform 12 repetitions with no voluntary interruption due to muscle fatigue.

The STEP session consists of three phases. It begins with a 10 min warm-up phase in which the patients can choose, according to their preferences, to walk in an outdoor circuit in a treadmill or use a stationary bicycle in a comfortable intensity. The second (conditioning) phase consists of $40 \mathrm{~min}$ of strengthening exercises (resistance training) of the lower limb and trunk muscles, and neuromuscular training involving balance exercises. Afterward, the session ends with a cool-down phase, consisting of static stretching exercises to potentially reduce musculoskeletal injuries and to maximise the benefit of the STEP protocol. $^{37}$ To ensure patient safeness and adherence, cardiac and respiratory frequencies and blood pressure are monitored at the beginning of each session, or if participants present an intense rate of perceived exertion according to the Borg scale while performing an exercise ${ }^{38} 39$

\section{PBM therapy protocol}

The PBM protocol was developed following the recommendations of the World Laser Therapy Association ${ }^{40}$ and previous randomised clinical trials for KOA. ${ }^{20} 224142$ Irradiation and treatment parameters are reported in accordance with good practice in clinical and laboratory PBM studies. ${ }^{434}$ A commercial hand-held device of a diode laser-semiconductor gallium aluminium arsenide-class 3B will be used (Recover, MMOptics, São Carlos, SP, Brazil). The devices have been assembled so that one is active and the other inactive (placebo), which were randomly labelled 'A' and ' $\mathrm{B}$ '. The only person who knows about the operation of the devices is an employee of the company who has provided the devices (therapists and participants are blinded). Irradiation parameters are wavelength of $808 \mathrm{~nm}$ (near infrared spectrum), maximum output power of $100 \mathrm{~mW} \pm 20 \%$, continuous waveform mode, laser beam spot size at a target of 0.03 $\mathrm{cm}^{2}$ and power density of $3.33 \mathrm{~W} / \mathrm{cm}^{2}$. The laser is regularly measured by an optical power metre (LabMax-TOP, Coherent, Santa Clara, California, USA). Four points at the medial side and four points at the lateral side of the affected knee will be irradiated perpendicularly on the joint line ${ }^{21}$-knees at approximately 45 degrees of 
Table 2 Detailed description of the outcome measurements

\begin{tabular}{|c|c|c|c|}
\hline Outcome measurement & Description of the test & Scoring & MCID \\
\hline Visual Analogue Scale & $\begin{array}{l}\text { The scale is placed in front of the patient who is } \\
\text { asked to rate their pain intensity in the prior week. }{ }^{45}\end{array}$ & $\begin{array}{l}\text { The scale ranges from } 0 \text { (no } \\
\text { pain) to } 10 \mathrm{~cm} \text { (maximum pain } \\
\text { intensity). }\end{array}$ & $\begin{array}{l}\text { A pain reduction of } 1.75 \mathrm{~cm} \\
\text { is recommended in } \mathrm{OA} \\
\text { research. }{ }^{46}\end{array}$ \\
\hline $\begin{array}{l}\text { Western Ontario \& } \\
\text { McMaster Universities } \\
\text { Osteoarthritis Index }\end{array}$ & $\begin{array}{l}\text { This self-report questionnaire assesses the problems } \\
\text { experienced by people with lower-limb OA in the } \\
\text { prior } 72 \text { hours. It contains } 24 \text { questions in three } \\
\text { domains: pain, stiffness and physical function. }\end{array}$ & $\begin{array}{l}\text { Each question is scored from } \\
0 \text { to } 4 \text {. The maximum score is } \\
96 . \text { High scores indicate worse } \\
\text { status. }\end{array}$ & $\begin{array}{l}\text { An improvement of } \\
12 \% \text { from baseline is } \\
\text { recommended in OA } \\
\text { research. }{ }^{49}\end{array}$ \\
\hline Stair climb test & $\begin{array}{l}\text { The participant is positioned in front of the stairs } \\
\text { and, at the therapist's signal, he/she has to climb } \\
\text { the indicated steps (we used a nine-step stair) } \\
\text { and descend promptly, being able to use the } \\
\text { handrail as a security instrument. We used } 20 \mathrm{~cm} \\
\text { steps height, a handrail stair in an illuminated } \\
\text { environment, free of traffic or external distractions. } \\
\text { Moreover, a pretest was conducted to identify the } \\
\text { need for safety measures. }\end{array}$ & $\begin{array}{l}\text { The final score was calculated } \\
\text { based on the time the } \\
\text { participant took to perform the } \\
\text { test and compared it with the } \\
\text { normative values available for } \\
\text { the test. }\end{array}$ & $\begin{array}{l}\text { A reduction of } 5.5 \mathrm{~s} \text { in the } \\
\text { test is the recommended } \\
\text { MCID in OA research. }\end{array}$ \\
\hline
\end{tabular}

OA, osteoarthritis; MCID, minimum clinically important difference.

flexion $^{23}$ — with the energy of $6 \mathrm{~J}$ per point, totalling an energy of $48 \mathrm{~J}$ per session ${ }^{22}$ in all 24 sessions.

\section{Outcome measurements}

A baseline assessment (A1) is performed before the 8-week intervention period, and a postintervention assessment (A2) right after the treatment period. For residual effects of the interventions, 3-month (A3) and 6-month (A4) follow-up assessments are performed. To reduce bias, two blinded assessors have been previously trained in our research laboratory and follow standardised scripts to give explanations regarding the general aim of the study. ${ }^{30}$ The participants are evaluated by the same assessor. Medication intake and physical activity level are tracked with logbooks given to the participants at baseline assessment (for the eight subsequently weeks) and immediately after treatment (for the 3-month follow-up period). All participants are advised to not practice any other type of regular physical exercises during the study protocol that could compete with the STEP protocol. Table 2 describes the outcome measurements included in this trial and the recommended estimate of the minimum clinically important difference (MCID) for each one. In summary, pain intensity, knee subjective and objective physical function, and QoL are assessed.

\section{Primary outcome}

The primary outcome is pain intensity at rest and on movement assessed with a $10 \mathrm{~cm}$ Visual Analogue Scale. This self-reported pain score is a valid and reliable measure among people with OA. ${ }^{45}$ The Visual Analogue Scale is administered at baseline, right after treatment, at 3-month and 6-month follow-up periods. 


\section{Secondary outcomes}

The WOMAC Index is used to evaluate self-reported pain, stiffness and physical function of the participants. Performance-based physical tests are used: the $30 \mathrm{~s}$ chairstand test, the stair-climb test and the $40 \mathrm{~m}$ fast-paced walk test. Also, the 36-Item Short-Form questionnaire is applied to assess health-related QoL.

\section{Randomisation}

Eligible people who consent to participate are randomly allocated into three groups: (1) control group that will receive STEP only, (2) STEP+active PBM group and (3) STEP+sham (inactive) PBM group. The randomisation schedule (random permuted blocks) has been prepared by the biostatistician on an electronic randomisation plan generator (http://www.randomization.com). The allocation of the participants is concealed, and a list with this information is locked in an opaque, sealed envelope that is stored in a central location under the supervision of a researcher who is not involved in this trial. This same researcher has been responsible for revealing group allocation to the therapists just before the intervention onset. $^{30}$

\section{Sample size}

We aimed to detect a MCID of $1.75 \mathrm{~cm}$ units on the Visual Analogue Scale for knee pain. ${ }^{46}$ In addition, we aimed to detect an MCID of 30 points on the WOMAC global score. ${ }^{47}$ Calculations were based on an analysis of covariance adjusting for baseline outcome scores, assuming between-patient $\mathrm{SD}$ of $2.0 \mathrm{~cm}$ for pain and 45 points for WOMAC global score. Based on these criteria, to provide an $80 \%$ statistical power with a significance level of 0.05 , 37 participants with KOA are required in each group. To allow possible dropouts during the intervention period (estimated at 10\%), 40 participants will be recruited per group, totalling a sample of 120 participants.

\section{Data management and statistical analyses}

Data are collected through digital forms and are directly structured on an electronic database, supported by a password-protected cloud-based management system that preserves the integrity and security of the participants' data. At the end of the data collection of all measurements, the statistical analyses will be performed by a blinded assessor using commercial software. The KolmogorovSmirnov test will be applied to evaluate data distribution. If the distribution is not normal, non-parametric tests will be used. For normal distributions, a two-factor analysis of variance will be conducted for the primary outcome (Visual Analogue Scale for pain) and the secondary outcomes, with time (baseline, postintervention and follow-up periods) as the within-subject factor and group (STEP, STEP+PBM and STEP+sham PBM) as the betweensubject factor. In addition, the Tukey test will be used for post hoc analysis when necessary and an intention-to-treat analysis will be performed for all randomised participants. Missing data will be replaced using the expectation maximisation method. Between-group differences and their $95 \%$ CIs will be reported and interpreted against the nominated thresholds for MCID. For outcomes where the MCID are not nominated, Cohen's $d$ coefficient will be calculated to aid interpretation. An effect size $>0.8$ will be considered large, around 0.5 moderate and $\leq 0.2$ small. $^{48}$

\section{ETHICS AND DISSEMINATION}

All participants provide written informed consent (online supplementary appendix B) after verbal and written explanations of the study and they have the opportunity to ask questions. Participants are free to withdraw from the trial at any time without prejudice to future treatment. Results will be presented at scientific meetings and published in peer-reviewed journals. All publications and presentations related to the study will be authorised and reviewed by the study investigators.

\section{TRIAL STATUS}

The trial is currently recruiting and is expected to be completed (including follow-up assessments) by June 2020.

Contributors AESJ, LOD, PRS, FAS and TFS: designed the study protocol; revised and produced the final version; read and approved the final version of the manuscript. AESJ and LOD: wrote the manuscript. AESJ: takes responsibility for the integrity of the work.

Funding AESJ and LOD were financially supported by Sao Paulo ResearchFoundation (FAPESP, Process \#2017/00062-7 and \#2015/21422-6,respectively), by the Coordenação de Aperfeiçoamento de Pessoal de Nível Superior (CAPES, Process \#1662695-001), and by the Conselho Nacional de Desenvolvimento Científico e Tecnológico (CNPQ, Process \#302169/2018).

Competing interests None declared.

Patient and public involvement Patients and/or the public were not involved in the design, or conduct, or reporting, or dissemination plans of this research.

Patient consent for publication Obtained.

Provenance and peer review Not commissioned; externally peer reviewed.

Open access This is an open access article distributed in accordance with the Creative Commons Attribution Non Commercial (CC BY-NC 4.0) license, which permits others to distribute, remix, adapt, build upon this work non-commercially, and license their derivative works on different terms, provided the original work is properly cited, appropriate credit is given, any changes made indicated, and the use is non-commercial. See: http://creativecommons.org/licenses/by-nc/4.0/.

\section{ORCID iDs}

Ana E S Jorge http://orcid.org/0000-0003-0427-0158

Lucas 0 Dantas http://orcid.org/0000-0002-6188-7552

Paula R M S Serrão http://orcid.org/0000-0002-4547-9161

Francisco Alburquerque-Sendín http://orcid.org/0000-0002-3892-8440

Tania F Salvini http://orcid.org/0000-0002-6353-6393

\section{REFERENCES}

1 Hunter DJ, Osteoarthritis HDJ. Osteoarthritis. Best Pract Res Clin Rheumatol 2011;25:801-14.

2 Johnson VL, Hunter DJ. The epidemiology of osteoarthritis. Best Pract Res Clin Rheumatol 2014;28:5-15.

3 Allen K, Golightlya YM. Epidemiology of osteoarthritis: state of the evidence. Curr Opin Rheumatol 2015;27:276-83.

4 Global Burden of Disease Study 2013 Collaborators. Global, regional, and national incidence, prevalence, and years lived with disability for 
301 acute and chronic diseases and injuries in 188 countries, 19902013: a systematic analysis for the global burden of disease study 2013. Lancet 2015;386:743-800.

5 Hunter DJ, Schofield D, Callander E. The individual and socioeconomic impact of osteoarthritis. Nat Rev Rheumatol 2014;10:437-41.

6 Hochberg MC, Altman RD, April KT, et al. American College of rheumatology 2012 recommendations for the use of nonpharmacologic and pharmacologic therapies in osteoarthritis of the hand, hip, and knee. Arthritis Care Res 2012;64:465-74.

7 Fernandes L, Hagen KB, Bijlsma JWJ, et al. EULAR recommendations for the non-pharmacological core management of hip and knee osteoarthritis. Ann Rheum Dis 2013;72:1125-35.

8 Zhang W, Moskowitz RW, Nuki G, et al. OARSI recommendations for the management of hip and knee osteoarthritis, part II: OARS evidence-based, expert consensus guidelines. Osteoarthritis Cartilage 2008;16:137-62.

9 Fransen M, Mcconnell S, Ar H, et al. Exercise for osteoarthritis of the knee. Cochrane Libr 2015;1:1-144.

10 Hunter DJ, Bierma-Zeinstra S. Osteoarthritis. Lancet 2019;393:1745-59.

11 Nicolson PJA, Bennell KL, Dobson FL, et al. Interventions to increase adherence to therapeutic exercise in older adults with low back pain and/or hip/knee osteoarthritis: a systematic review and metaanalysis. Br J Sports Med 2017:51:791-9.

12 Dobson F, Bennell KL, French SD, et al. Barriers and facilitators to exercise participation in people with hip and/or knee osteoarthritis. Am J Phys Med Rehabil 2016;95:1.

13 Collins NJ, Hart HF, Mills KAG. Osteoarthritis year in review 2018: rehabilitation and outcomes. Osteoarthritis Cartilage 2019;27:378-91.

14 WM O, Thae Bo M. Efficacy of physical modalities in knee osteoarthritis: recent recommendations. Int J Phys Med Rehabil 2016;04:3-4.

15 Anders JJ, Lanzafame RJ, Arany PR. Low-Level light/laser therapy versus photobiomodulation therapy. Photomed Laser Surg 2015;33:183-4

16 Peplow PV, Chung T-Y, Baxter GD. Application of low level laser technologies for pain relief and wound healing: overview of scientific bases. Physical Therapy Reviews 2010;15:253-85

17 Bjordal JM, Couppé C, Chow RT, et al. A systematic review of low level laser therapy with location-specific doses for pain from chronic joint disorders. Aust J Physiother 2003;49:107-16.

18 Hamblin MR. Can osteoarthritis be treated with light? Arthritis Res Ther 2013;15:ar4354:120

19 Bjordal JM, Johnson MI, Lopes-Martins RAB, et al. Short-Term efficacy of physical interventions in osteoarthritic knee pain. A systematic review and meta-analysis of randomised placebocontrolled trials. BMC Musculoskelet Disord 2007:8:1-14.

20 Alghadir A, Omar MTA, Al-Askar AB, et al. Effect of low-level laser therapy in patients with chronic knee osteoarthritis: a single-blinded randomized clinical study. Lasers Med Sci 2014;29:749-55.

21 Fukuda VO, Fukuda TY, Guimarães M, et al. Short-Term efficacy of low-level laser therapy in patients with knee osteoarthritis: a randomized placebo-controlled, double-blind clinical trial. Rev Bras Ortop 2011;46:526-33.

22 Hegedüs B, Viharos L, Gervain M, et al. The effect of low-level laser in knee osteoarthritis: a double-blind, randomized, placebocontrolled trial. Photomed Laser Surg 2009;27:577-84.

23 Kheshie AR, Alayat MSM, Ali MME. High-Intensity versus low-level laser therapy in the treatment of patients with knee osteoarthritis: a randomized controlled trial. Lasers Med Sci 2014;29:1371-6.

24 de Paula Gomes CAF, Leal-Junior ECP, Dibai-Filho AV, et al. Incorporation of photobiomodulation therapy into a therapeutic exercise program for knee osteoarthritis: a placebo-controlled, randomized, clinical trial. Lasers Surg Med 2018;50:819-28.

25 Alfredo PP, Bjordal JM, Junior WS, et al. Long-Term results of a randomized, controlled, double-blind study of low-level laser therapy before exercises in knee osteoarthritis: laser and exercises in knee osteoarthritis. Clin Rehabil 2018;32:173-8.

26 Stausholm MB, Naterstad IF, Joensen J, et al. Efficacy of low-level laser therapy on pain and disability in knee osteoarthritis: systematic review and meta-analysis of randomised placebo-controlled trials. BMJ Open 2019;9:e031142-13.

27 Huang Z, Chen J, Ma J, et al. Effectiveness of low-level laser therapy in patients with knee osteoarthritis: a systematic review and metaanalysis. Osteoarthritis Cartilage 2015;23:1437-44.

28 Rayegani SM, Raeissadat SA, Heidari S, et al. Safety and effectiveness of low-level laser therapy in patients with knee osteoarthritis: a systematic review and meta-analysis. J Lasers Med Sci 2017;8:S12-19.
29 Chan A-W, Tetzlaff JM, Altman DG, et al. Spirit 2013 statement: defining standard protocol items for clinical trials. Ann Intern Med 2013;158:200.

30 McAlindon TE, Driban JB, Henrotin Y, et al. OARSI clinical trials recommendations: design, conduct, and reporting of clinical trials for knee osteoarthritis. Osteoarthritis Cartilage 2015;23:747-60.

31 Hoffmann TC, Glasziou PP, Boutron I, et al. Better reporting of interventions: template for intervention description and replication (TIDieR) checklist and guide. BMJ 2014;348:g1687.

32 Boutron I, Altman DG, Moher D, et al. Consort statement for randomized trials of nonpharmacologic treatments: a 2017 update and a consort extension for nonpharmacologic trial Abstracts. Ann Intern Med 2017;167:40-7.

33 Altman R, Asch E, Bloch D, et al. Development of criteria for the classification and reporting of osteoarthritis. classification of osteoarthritis of the knee. diagnostic and therapeutic criteria Committee of the American rheumatism association. Arthritis Rheum 1986;29:1039-49.

34 Messier SP, Mihalko SL, Beavers DP, et al. Strength training for arthritis trial (start): design and rationale. BMC Musculoskelet Disord 2013;14:1.

35 Fransen M, McConnell S, Harmer AR, et al. Exercise for osteoarthritis of the knee: a Cochrane systematic review. $\mathrm{Br} J$ Sports Med 2015;49:1554-7.

36 Nóbrega SR, Ugrinowitsch C, Pintanel L, et al. Effect of resistance training to muscle failure vs. volitional interruption at high- and Low-Intensities on muscle mass and strength. J Strength Cond Res 2018;32:162-9.

37 Bennell KL, Dobson F, Hinman RS. Exercise in osteoarthritis: moving from prescription to adherence. Best Pract Res Clin Rheumatol 2014;28:93-117.

38 American Geriatrics Society Panel on Exercise and Osteoarthritis Exercise prescription for older adults with osteoarthritis pain: consensus practice recommendations. A supplement to the AGS clinical practice guidelines on the management of chronic pain in older adults. J Am Geriatr Soc 2001;49:808-23.

39 Vincent KR, Vincent HK. Resistance exercise for knee osteoarthritis. Pm R 2012;4:S45-52.

40 World Association of Laser Therapy (WALT). Consensus agreement on the design and conduct of clinical studies with low-level laser therapy and light therapy for musculoskeletal pain and disorders. Photomed Laser Surg 2006;24:761-2.

41 Alfredo PP, Bjordal JM, Dreyer SH, et al. Efficacy of low level laser therapy associated with exercises in knee osteoarthritis: a randomized double-blind study. Clin Rehabil 2012;26:523-33.

42 Montes-Molina R, Madroñero-Agreda MA, Romojaro-Rodríguez $A B$, et al. Efficacy of interferential low-level laser therapy using two independent sources in the treatment of knee pain. Photomed Laser Surg 2009;27:467-71.

43 Hamblin MR. How to write a good Photobiomodulation article. Photobiomodul Photomed Laser Surg 2019;37:325-6.

44 Jenkins PA, Carroll JD. How to report low-level laser therapy (LLLT)/ photomedicine dose and beam parameters in clinical and laboratory studies. Photomed Laser Surg 2011;29:785-7.

45 Hawker GA, Mian S, Kendzerska T, et al. Measures of adult pain: visual analog scale for pain (vas pain), numeric rating scale for pain (NRS pain), McGill pain questionnaire (MPQ), short-form McGill pain questionnaire (SF-MPQ), chronic pain grade scale (CpGs), short Form-36 bodily pain scale (SF-36 BPs), and measure of intermittent and constant osteoarthritis pain (ICOAP). Arthritis Care Res 2011;63 Suppl 11:240-52.

46 Bellamy N, Carette S, Ford PM, et al. Osteoarthritis antirheumatic drug trials. III. Setting the delta for clinical trials--results of a consensus development (Delphi) exercise. J Rheumatol 1992;19:451-7.

47 Fitzgerald GK, Fritz JM, Childs JD, et al. Exercise, manual therapy, and use of booster sessions in physical therapy for knee osteoarthritis: a multi-center, factorial randomized clinical trial. Osteoarthritis Cartilage 2016;24:1340-9.

48 Cohen JHillsdale NJ, ed. Statistical Power Analysis for the Behavioral Sciences. 2nd Ed, 1998.

49 Angst F, Aeschlimann A, Stucki G. Smallest detectable and minimal clinically important differences of rehabilitation intervention with their implications for required sample sizes using WOMAC and SF-36 quality of life measurement instruments in patients with osteoarthritis of the lower extremities. Arthritis Rheum 2001;45:384-91.

50 Escobar A, Quintana JM, Bilbao A, et al. Responsiveness and clinically important differences for the WOMAC and SF-36 after total knee replacement. Osteoarthritis Cartilage 2007;15:273-80.

51 Dobson F, Hinman RS, Roos EM, et al. OARSI recommended Performance-based tests to assess physical function in people 
diagnosed with hip or knee osteoarthritis. Osteoarthritis Cartilage 2013;21:1042-52.
52 Dobson F, Bennell KL, Hinman RS, et al. Recommended performance - based tests to assess physical function in people diagnosed with hip or knee osteoarthritis. Osteoarthr Res Soc Int 2013:1-26. 